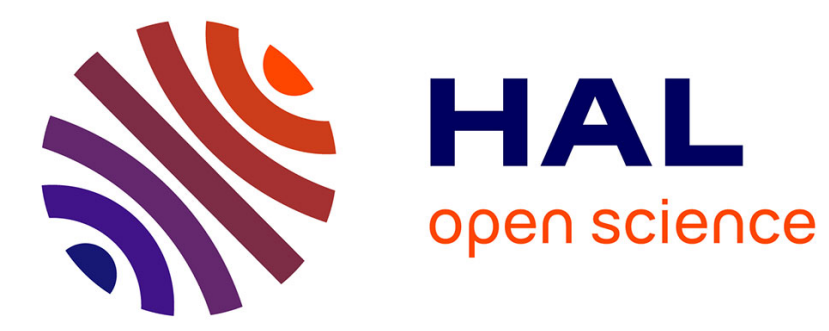

\title{
Identification and concentration measurements of atmospheric pollutants through a neural network analysis of photothermal signatures
}

K. Boccara, A. Boccara

\section{- To cite this version:}

K. Boccara, A. Boccara. Identification and concentration measurements of atmospheric pollutants through a neural network analysis of photothermal signatures. Journal de Physique IV Proceedings, 1994, 04 (C7), pp.C7-107-C7-110. 10.1051/jp4:1994727 . jpa-00253255

\section{HAL Id: jpa-00253255 \\ https://hal.science/jpa-00253255}

Submitted on 1 Jan 1994

HAL is a multi-disciplinary open access archive for the deposit and dissemination of scientific research documents, whether they are published or not. The documents may come from teaching and research institutions in France or abroad, or from public or private research centers.
L'archive ouverte pluridisciplinaire HAL, est destinée au dépôt et à la diffusion de documents scientifiques de niveau recherche, publiés ou non, émanant des établissements d'enseignement et de recherche français ou étrangers, des laboratoires publics ou privés. 


\title{
Identification and concentration measurements of atmospheric pollutants through a neural network analysis of photothermal signatures
}

\author{
K. Boccara and A.C. Boccara* \\ Process Engineering UMIST, Manchester M601 QD, U.K. \\ * Laboratoire d'Optique, ESPCI, UPR A0005 du CNRS, 10 rue Vauquelin, 75005 Paris, France
}

\begin{abstract}
We propose here to use a neural network as a help in the identification of individual components of a gaz mixture and in the evaluation of the concentration level of each component as they appear in real photoacoustic spectra in presence of background signals and noises. The method is based on the dependance of the activation functions with regard to the input level controled variation and on the desactivation of the first activated outputs.
\end{abstract}

Pollutants are now world-wide considered as short-term poisons dangerous to life on earth and longterm perturbators of the atmospheric transparency to $\mathrm{UV}\left(\mathrm{O}_{3}\right)$, visible and infrared (green house effect) radiations. The green house effect is not only caused by $\mathrm{CO}_{2}$ but also by other heat trapping gases. Heattrapping gases in the atmosphere other than $\mathrm{CO}_{2}$ are mainly methane (100 times less concentrated but 20 times more heat absorbent), nitrous oxide $\left(\mathrm{N}_{2} \mathrm{O}\right)$, ozone $\left(\mathrm{O}_{3}\right)$ and the chlorofluorocarbons (CFC's). By the mid-1980's, these gases had reached levels at which their combined effect approached that of carbon dioxide [1] [2]. Indeed, $\mathrm{CO}_{2}$, nowadays, makes up about $50-55 \%$ of the global warming problem while $\mathrm{CH}_{4}$ and CFC's each account for $20-25 \%$ [3].

Photoacoustic and photothermal detection and measurements of low concentrated atmospheric pollutants are now well established techniques [4,5] for low concentration measurements of such gases. Most of the time the heating source is a molecular laser (e.g. $\mathrm{CO}$ or $\left.\mathrm{CO}_{2}\right)$ and the "beating" between the discrete lines of these (low pressure) lasers and the vibrational-rotational levels of the molecules provide a clear "signature" of the pollutant. Fig. 1 shows such signature (left column from top to bottom: $\mathrm{C}_{2} \mathrm{H}_{4}, \mathrm{C}_{6} \mathrm{H}_{6}$, $\mathrm{NH} 3, \mathrm{SO}_{2}, \mathrm{CF}_{2} \mathrm{Cl}_{2}, \mathrm{CFCl}_{3}$ ) for $50 \mathrm{CO}_{2}$ laser lines in the 9.6 and $10.6 \mu \mathrm{m} \mathrm{R}$ and $\mathrm{P}$ branches

This simple situation turns out to be more tricky when the signal is generated by a mixture of gazes (Fig.l middle) and when background (e.g. smoke particles) and or random noises (e.g. of the detector) are present. (Fig.1 right column). Various elegant physical approaches such as Stark modulation could be used for a more selective identification of the species [5].

Artificial neural networks NN are acknowledged as efficient classifiers able to discriminate various classes associated with the representations of objects. (i.e. : numbers, letters, shapes, images...). One of their main characteristics is their strong resistance to noise. In this paper we have tried to extend the simple role of classifier a step further and to use the output signals of the neurons not only as a help in the identification of a particular gas in a mixture but also in the evaluation of its concentration level. Our conjecture is that if one specific gas spectrum can "activate" the NN output the other gazes will act as noise.

Let us underline that the trained NN acts as a classifier and despite of its non linear response we will use it as a highly selective filter which is able to discriminate between a few gases through the following proposed process of selection.

First in order to stimulate a realistic problem of spectral discrimination we synthesize various signals which correspond to various "difficult" gaz mixtures (which means concentration giving almost equivalent maximum signals).

We introduce here a two step process using neural networks which seems to be helpful in solving this complex problem : in a first step a neural network $(\mathrm{NN})$ is trained to identify the individual spectra of selected 


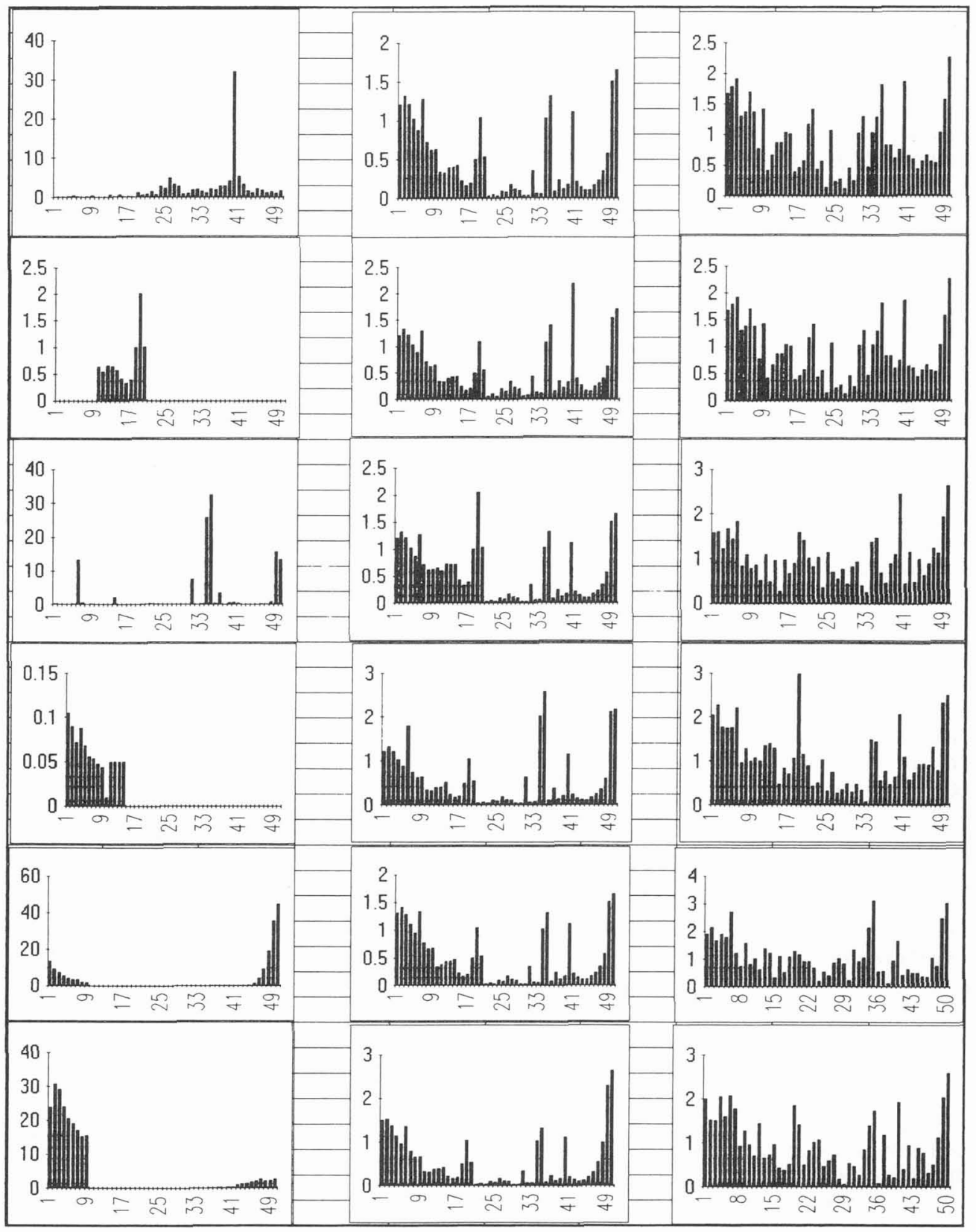

Fig. 1 : Spectra of isolated gazes (left) mixtures of these gazes without (middle) and with (right) a noiselevel. 
gases to be detected (e.g. six gases in our case) in presence of a strong noise level (typically a signal to noise ratio $\mathrm{S} / \mathrm{N} \cong 2$ on the largest signal gives $95 \%$ of success). Then we scale the complex signals to be analyzed at the input of the $\mathrm{NN}$ in order to stimulate one output corresponding to a first class.and the signal corresponding to this class is taken out from the data and the process goes on.

As example we analyze the activations induced by the six mixtures on the trained NN. The NN was either a 1 hidden or a 2 hidden layers back-propagation type (the results being almost equivalent with both types) with 50 inputs and 6 outputs corresponding to the gases to be analyzed. Fig. 1 shows the most activated outputs activation functions when the input signals are multiplied successively by $0,0.1,0.2,0.5$, $1,2,5$ and 10 for the six mixtures of fig 1 .

The ideal activation function is a sigmoid (output level between -0.5 , and +0.5 ) and we can easily see that some mixtures are more efficient than others to generate a "neat" activation level. We can now try to apply the suggested process of successive inhibition to some of these gaz mixtures.

For instance the $3 \mathrm{rd}$ mixture (from the top in fig. 1) activated the $\mathrm{NH}_{3}$ response with a neat activation function so we can, by comparison to the isolated gases activation, suppress the main part of the concentration in the mixture. The new mixture is then presented to activate the $\mathrm{NN}$ and the $\mathrm{SO}_{2}$ signal is clearly activated (Fig. 3 top).

After extraction of the $\mathrm{SO}_{2}$ contribution to the residual mixture the next $\mathrm{NN}$ response gives a rather confusing situation : first $\mathrm{CFCl}_{3}$ is activated (left) and then inhibitive interactions take place which cancels this activation and stimulate again an $\mathrm{NH}_{3}$ response (right).

We have checked that this last point is an artefact and that the $\mathrm{CFCl}_{3}$ level can be reasonably estimated. The last step in fig. 3 (bottom) clearly exhibits the activation function of $\mathrm{C}_{6} \mathrm{H} 6$ which takes place without competition but the error on the concentration level is within $50 \%$.

In this very preliminary study we have tried to introduce an helpful process which can be used in atmospheric gas mixture analysis. The NN are now available as fast microcircuits whose inputs can be activated in parallel and the procedure that we have proposed can be easily and efficiently implemented with such chips.

[1] T.E. Graedel and P.J. Crutzen: The changing atmosphere : Scient. Am. 2611989.

[2] R.A. Houghton and G.M. Woodwell, Global climatic change : Scient. Am. 2601989.

[3] K. Boccara, Litterature review : $\mathrm{CO}_{2}$ and global warning (unpublished).

[4] M.W. Sigrist, S. Bernegger and P.L. Meyer, in Photoacoustic Photothermal and Photochemical Processes in Gases, (P. Hess, Ed.) Springer-Verlag, Berlin (1989)

[5] D. Bicanic, F. Harren and J. Reiss, in Photoacoustic Photothermal and Photochemical Processes in

Gases, (P. Hess, Ed.) Springer-Verlag, Berlin (1989) 


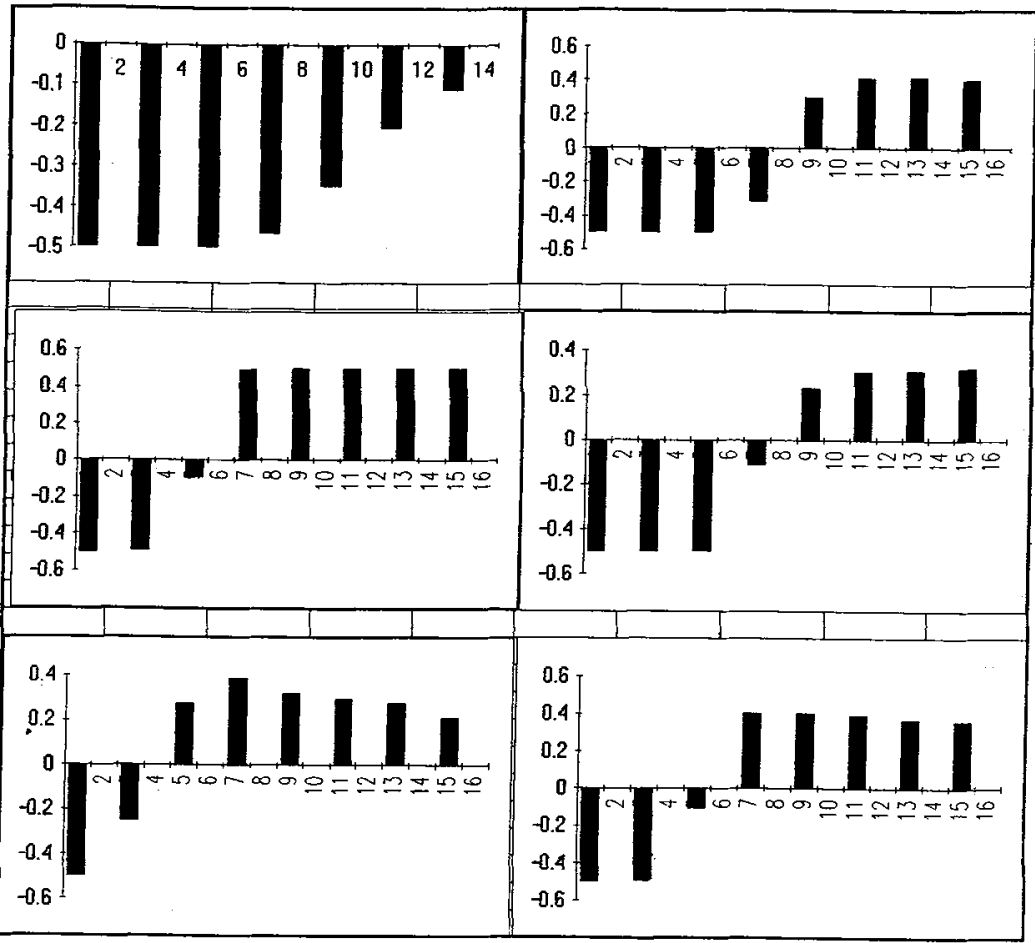

Fig. 2 : Activation functions of the dominant outputs when varying the amplitude of the input signal for the gaz mixtures.

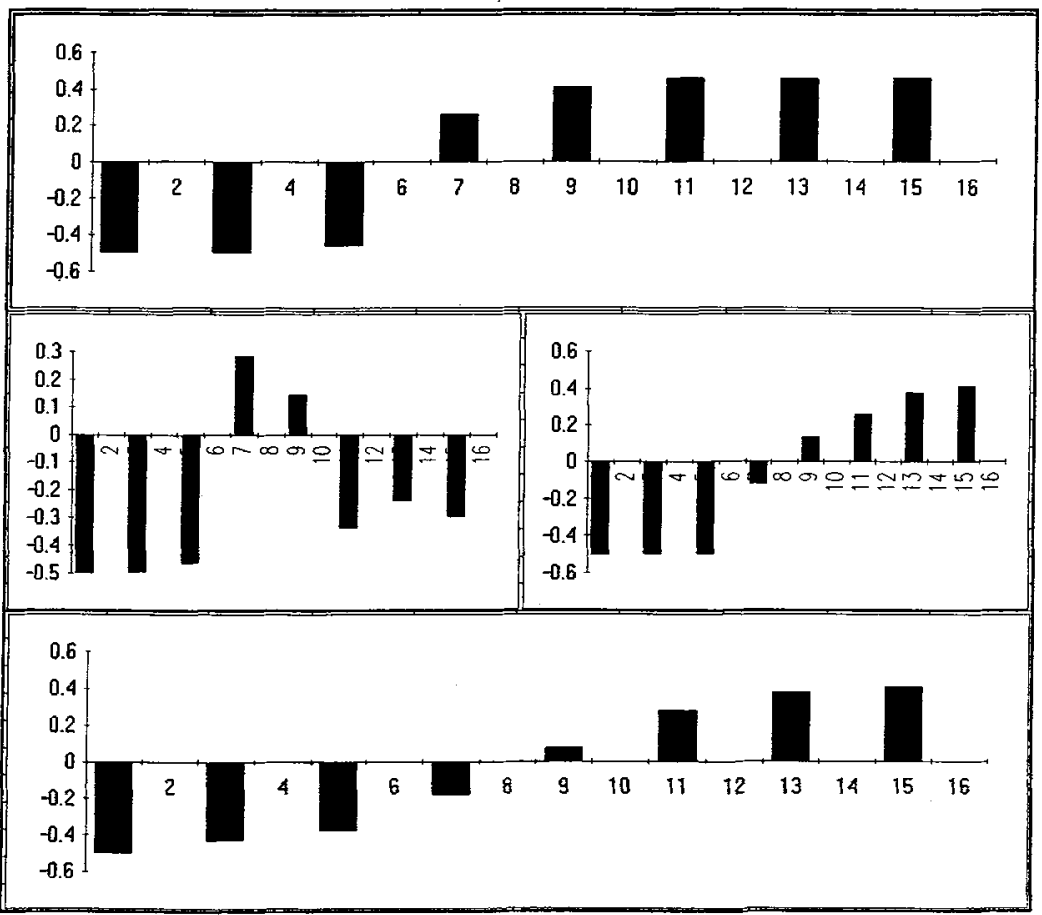

Fig. 3 : Successive activation functions of mixture 3 when the gazes stimulating the output of the NN are withdrown from the mixture. 